\title{
Western North Pacific Tropical Cyclone Intensity and ENSO
}

\author{
SuZANA J. CAMARGo \\ International Research Institute for Climate Prediction, The Earth Institute of Columbia University, Palisades, New York
}

Adam H. Sobel

Department of Applied Physics and Applied Mathematics, and Department of Earth and Environmental Sciences, Columbia University, New York, New York

(Manuscript received 10 June 2004, in final form 30 November 2004)

\begin{abstract}
The influence of the El Niño-Southern Oscillation (ENSO) on tropical cyclone intensity in the western North Pacific basin is examined. Accumulated cyclone energy (ACE), constructed from the best-track dataset for the region for the period 1950-2002, and other related variables are analyzed. ACE is positively correlated with ENSO indices. This and other statistics of the interannually varying tropical cyclone distribution are used to show that there is a tendency in El Niño years toward tropical cyclones that are both more intense and longer-lived than in La Niña years. ACE leads ENSO indices: during the peak season (northern summer and fall), ACE is correlated approximately as strongly with ENSO indices up to six months later (northern winter), as well as simultaneously. It appears that not all of this lead-lag relationship is easily explained by the autocorrelation of the ENSO indices, though much of it is. Interannual variations in the annual mean lifetime, intensity, and number of tropical cyclones all contribute to the ENSO signal in ACE, though the lifetime effect appears to be the most important of the three.
\end{abstract}

\section{Introduction}

The relationship between the El Niño-Southern Oscillation (ENSO) and western North Pacific (WNP) tropical cyclones (TCs) has been examined by many authors. The relationship is of obvious interest since statistically based seasonal forecasts of tropical cyclone activity in the western North Pacific use ENSO as one of the main predictors (Chan et al. 1998 2001), though other effects such as the quasi-biennial oscillation (Chan 1995) and Madden-Julian oscillation (e.g., Liebmann et al. 1994; Sobel and Maloney 2000) also affect western North Pacific tropical cyclone activity. Most studies have focused on the location of cyclogenesis and the total number of tropical cyclones. The main emphasis here is on the influence of ENSO on tropical cyclone intensity.

Atkinson (1977) first noted an above-normal number

Corresponding author address: Dr. Suzana J. Camargo, International Research Institute for Climate Prediction, LamontDoherty Earth Observatory, Columbia University, 61 Route 9W, P.O. Box 1000, Palisades, NY 10964.

E-mail: suzana@iri.columbia.edu of tropical cyclones developing in the eastern part of the western North Pacific during the El Niño of 1972. Since then many authors have examined the relationship between ENSO and the number of western North Pacific tropical cyclones. The results have not been consistent in all cases, presumably because of differences in both data and technique (e.g., Ramage and Hori 1981; Pan 1982; Chan 1985; Dong 1988; Wu and Lau 1992; Lander 1994). Though there is no significant linear relation between the number of tropical cyclones and ENSO, a nonlinear relation between ENSO and the number of tropical cyclones has been found in several studies, being evident when the ENSO forcing is strong (Chan 1985; Chan and Shi 1996; Chan 2000; Chen et al. 1998; Wang and Chan 2002). This relationship is the basis of Chan's statistical seasonal predictions (Chan et al. 1998, 2001).

A well-documented influence of ENSO on WNP tropical cyclone activity is that on the mean location of tropical cyclone genesis (e.g., Pan 1982; Chan 1985, 2000; Wang and Chan 2002; Chia and Ropelewski 2002). In El Niño years, there is usually a southeastward displacement of the mean tropical storm and typhoon genesis region. 
In El Niño years, a greater number of tropical cyclones form in the central Pacific region (Chu and Wang 1997; Clark and Chu 2002). Some of these cyclones then move into the western North Pacific, as was the case of Ele and Huko in 2002 (an El Niño developing year). Differences in landfall patterns in different regions of Asia due to ENSO have been discussed in a few studies (e.g., Saunders et al. 2000; Elsner and Liu 2003; Wu et al. 2004), as well as the differences in rainfall patterns in different ENSO phases (Rodgers et al. 2000).

In 1997, the year of the strongest El Niño of the century, the western North Pacific had 23 typhoons (the second-largest number of any year on record), an unprecedented number of very intense tropical cyclones (11 became supertyphoons), and a large eastward displacement of the genesis location. That year, two tropical cyclones (Oliwa and Paka) formed in the central North Pacific (east of the data line) and entered the western North Pacific before reaching supertyphoon intensity (Lander and Guard 2001).

Wang and Chan (2002) also noted that the mean lifetime of tropical cyclones tends to increase during strong El Niño events, as more tropical cyclones form in the southeast quadrant of the WNP, thus experiencing a longer traveling time (westward and northward) before encountering the continent or colder midlatitude water. This is one possible explanation for the effect we document in more detail here, the tendency toward more intense typhoons in El Niño years.

A few previous studies have briefly documented a relationship between TC intensity and ENSO. The main ones of which we are aware are those of Pudov and Petrichenko $(1998,2001)$, who found an increase in the intensity of tropical cyclones in El Niño years. Chia and Ropelewski (2002), in their Fig. 6, showed an ENSO-related shift in the number of storms in different intensity categories, in the sense of a greater number of intense storms during El Niño. We are not aware of a more thorough examination of the relationship between ENSO and TC intensity than the relatively cursory ones mentioned above. This is surprising given the large number of studies on other aspects of the ENSOtropical cyclone relationship. Chan and Liu (2004) discuss in a recent paper some aspects of this relationship and their study is complementary to ours.

Here, we examine the relationship between ENSO and several tropical cyclone-related variables in the western North Pacific. We focus on the accumulated cyclone energy (ACE; Bell et al. 2000), a quantity that combines the number, lifetimes, and intensities of tropical cyclones occurring in a basin over a given period of time. The ACE index for a basin is defined as the sum of the squares of the estimated 6-hourly maximum sustained surface wind speed (originally in knots ${ }^{2}$; we use $\mathrm{m} \mathrm{s}^{-2}$ ) for all tropical cyclones in the basin having tropical storm intensity or greater (tropical depressions not included) summed over all 6-h periods.

We favor ACE as an index of tropical cyclone activity for a few reasons. It is useful for computing correlations and regressions with other climate variables of interest, as it is a continuous variable, in the sense that its possible values are not quantized, as the number of tropical cyclones, in particular, is. Its integration of storm intensity over the lifetime of each storm as well as over all storms is, arguably, appropriate for indexing the effect of tropical cyclones on climate. The fact that ACE measures storm intensity by maximum wind speed (squared), as opposed to a more integral measure that would account for storm size, is partly imposed by the fact that maximum wind speed is a variable for which we have data.

In section 2, the datasets and the methods used will be described. Section 3 shows the relation of ACE and ENSO, while section 4 discusses the relation of ACE and other tropical cyclone activity indices. The conclusions are given in section 5 .

\section{Data and methodology}

We use the best-track dataset from the Joint Typhoon Warning Center (JTWC 2005) in the period 1950-2002 to construct the ACE and other indices of tropical cyclone activity. As the observed data quality is considerably poorer in the presatellite than the postsatellite era, all our calculations have been done using both the longer period 1950-2002 and the postsatellite era only (1970-2002). In most cases, only the results for the latter period are shown.

The monthly sea surface temperature Niño indices (1950-2002; Barnston et al. 1997) and the Southern Oscillation index (SOI; 1951-2002; Troup 1965) were obtained from the Climate Prediction Center (CPC) Web site (CPC 2005). El Niño and La Niña years are defined according to the value of the Niño-3.4 index (Barnston et al. 1997) averaged over the season of interest. In the case of tropical cyclone activity indices for a whole year or June-July-August-September-October-November (JJASON), Niño-3.4 is averaged over the peak of the typhoon season, July-August-September-October (JASO), shown in the time series in Fig. 1a. The $13 \mathrm{yr}$ (approximately $25 \%$ of the 53 -yr period) with the largest (smallest) values of Niño-3.4 are defined as El Niño (La Niña) years; the other 27 are defined as neutral years. This definition avoids using thresholds, which are season dependent and can have asymmetries between cold and warm events. These El Niño and La Niña 
(a)
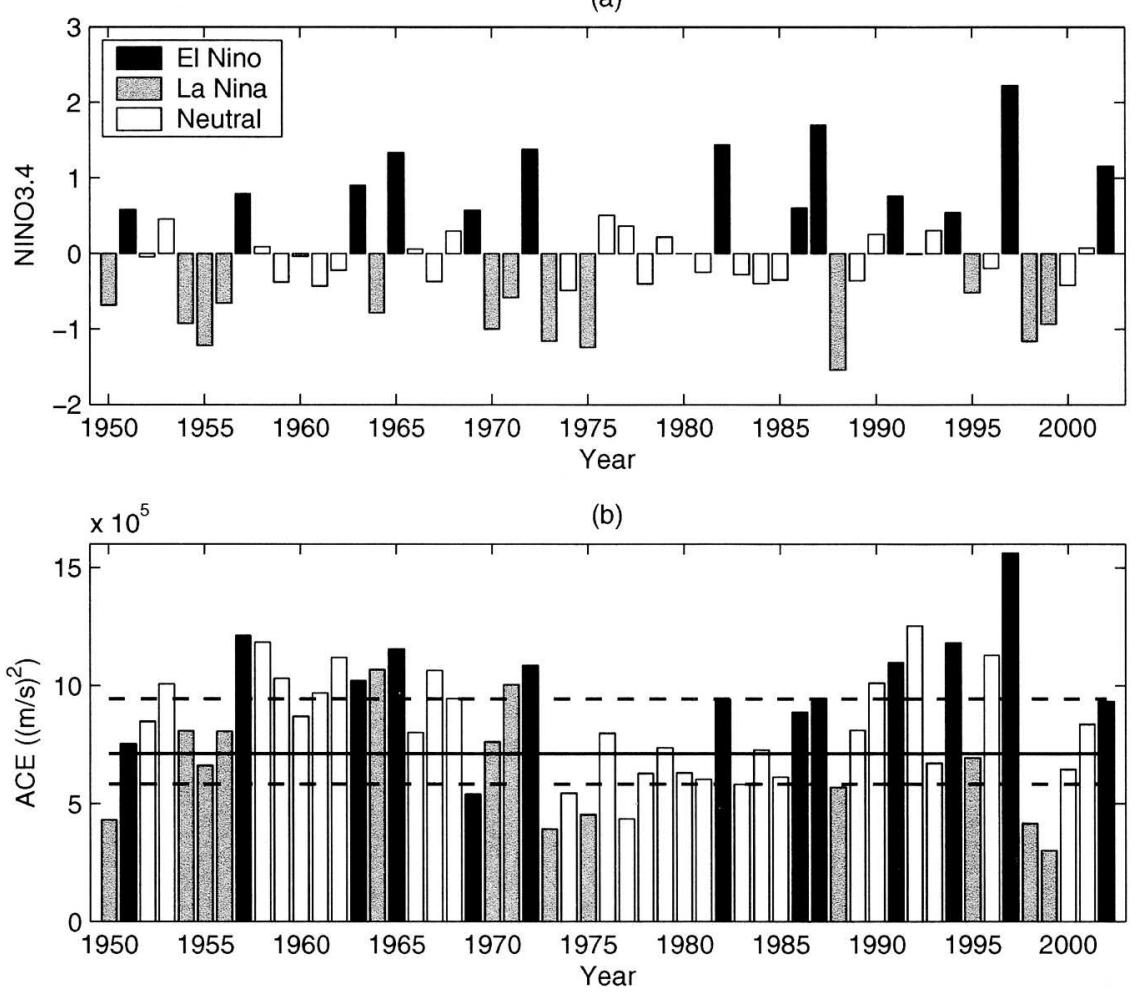

FIG. 1. (a) Niño-3.4 index $\left({ }^{\circ} \mathrm{C}\right)$ for the season JASO in the period 1950-2002. (b) ACE per year in the period 1950-2002. The horizontal lines show the 25th and 75th percentiles (dashed) and median (solid) in the period 1970-2002.

years correspond to the Northern Hemisphere summers before the peaks of the ENSO events (which usually occur in Northern Hemisphere winter), defined using other, more traditional definitions (e.g., Trenberth 1997; as discussed in Goddard and Dilley 2005).

The significance of correlations was determined using the $t$ test $(95 \%$ level). The Kolmogorov-Smirnov test (Sheskin 2000) and bootstrap calculations (95\% level) were used to determine whether entire distributions of quantities such as ACE depend on ENSO phase.

\section{ACE and ENSO}

In Fig. 1b the time series of ACE per year is shown. The year with the smallest ACE on record is a La Niña year (1999), and the highest ACE value occurred in the summer prior to the strongest El Niño year of the past century, 1997. Of the 13 El Niño years, only one (1969) has an ACE value below the median of the period 1970-2002 (climatology), and eight of these years are above the 75th percentile of the climatology. In contrast, 8 of the 13 La Niña years have ACE values below the median, with 6 of them below the 25th percentile.
Only one La Niña year with above-normal ACE occurred in the last $30 \mathrm{yr}$ (1971), when the data are more reliable. This could reflect either a stronger connection with ENSO after 1970 or problems with the reliability of the data prior to 1970 .

ACE is not only significantly correlated with Niño3.4, but also with other ENSO indices. In Table 1 we show the simultaneous correlations of ACE with various ENSO indices (JASO). ACE has significant correlations with all these indices, with the exception of ACE in JASO and Niño-1+2. The highest correlations occur for Niño-3.4 and Niño-4, implying that the central Pacific is the most important region for western North Pacific tropical cyclone activity. Higher correlation values occur when the whole year is considered. To further

TABLE 1. Correlations of ACE (per year, JJASON, and JASO) with Niño-1+2, Niño-3, Niño-3.4, Niño-4, and SOI in JASO in the period 1970-2002. Significant correlations are in boldface.

\begin{tabular}{lccccc}
\hline \hline ACE & Niño-1+2 & Niño-3 & Niño-3.4 & Niño-4 & SOI \\
\hline Year & $\mathbf{0 . 4 3}$ & $\mathbf{0 . 6 3}$ & $\mathbf{0 . 7 0}$ & $\mathbf{0 . 6 8}$ & $\mathbf{- 0 . 5 6}$ \\
JJASON & $\mathbf{0 . 3 7}$ & $\mathbf{0 . 5 4}$ & $\mathbf{0 . 6 1}$ & $\mathbf{0 . 6 3}$ & $\mathbf{- 0 . 5 1}$ \\
JASO & 0.33 & $\mathbf{0 . 5 3}$ & $\mathbf{0 . 6 2}$ & $\mathbf{0 . 6 3}$ & $\mathbf{- 0 . 5 2}$ \\
\hline
\end{tabular}




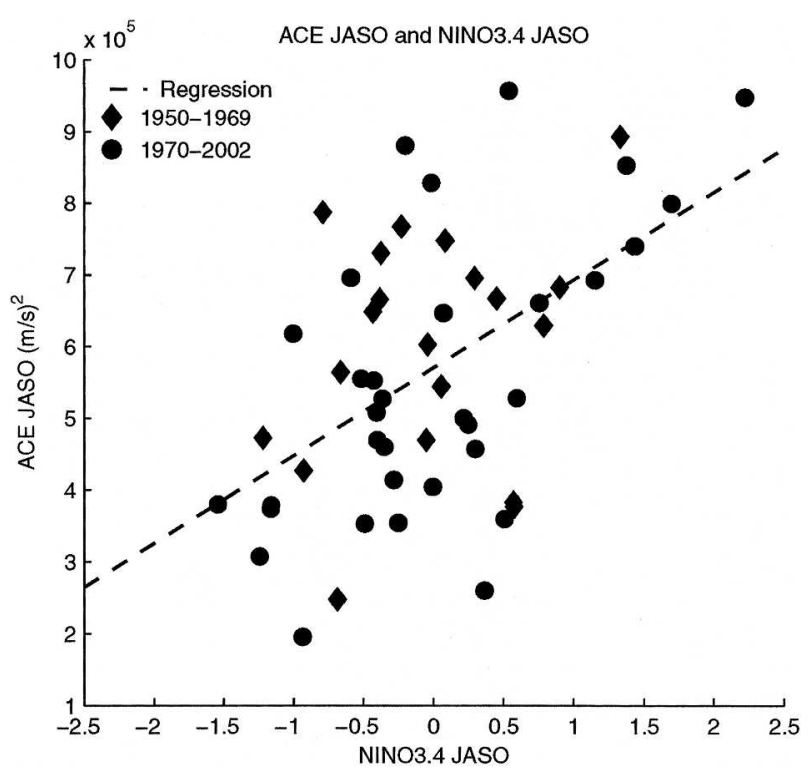

FIG. 2. Scatterplot of ACE $\left(\mathrm{m} \mathrm{s}^{-2}\right)$ and Niño-3.4 $\left({ }^{\circ} \mathrm{C}\right)$ for JASO in the period 1950-2002; the dashed line is the linear regression.

test the ACE and ENSO relationship, we used not only correlations, but also (not shown) rank correlation, Sommer's delta, and Kendall's tau (Sheskin 2000), obtaining similar results.

In Fig. 2 the scatterplot of Niño-3.4 and ACE in JASO and the corresponding regression line are shown. There is a relationship between ACE and Niño-3.4 over the whole dynamic range of ENSO variability, though the relationship is most obvious for the largest El Niño events, consistent with the results of Wang and Chan (2002) on storm number.

Figure 3 shows the lag correlations of ACE at JASO with the Niño indices for different seasons. The autocorrelation of Niño-3.4 in the different seasons with itself at JASO of year 0 is also shown. Besides the high significant values of the simultaneous correlations (JASO of year 0) of ACE and the Niño indices, significant correlations with Niño-4 start as early as February-March-April (FMA) of the year that ENSO develops (year 0) and last until May-June-July (MJJ) of the year that the event ends (year +1$)$. It is interesting that the correlations stay high for such a long period. Much of this is surely due to the autocorrelation of the Niño indices (as shown in the figure for Niño-3.4), but nonetheless we find the structure of these curves somewhat surprising. In particular, while the autocorrelation of Niño-3.4 is much greater than the lag correlation of any ENSO index and ACE over most of the period for which any of the correlations are significant, the ACEENSO curves stay flat or even trend upward from northern fall through the following spring, while the
Niño-3.4 autocorrelation trends down during the same period. This suggests that the autocorrelation of the Niño indices is not the sole explanation for the fact that ACE leads some of them.

A related result led Pudov and Petrichenko (2001) to suggest that tropical cyclones cloud be used as an indicator in forecasting ENSO. The autocorrelation shows that in general, the current ENSO state is a much better indicator. However, the crossing of the Niño-3.4 autocorrelation curve with the others in the late spring or early summer of year +1 shows that ACE in JASO of year 0 becomes as good a predictor of some of the Niño indices as Niño-3.4 in JASO of year 0 at that point (past the "persistence barrier"), though both have at best marginal significance during that time.

In another study (Sobel and Camargo 2005) we argue, from a shorter time-scale analysis of the relationship between ACE and other atmosphere and ocean variables, that while typhoons certainly do not cause ENSO, they may play a small positive role in ENSO dynamics, helping a developing El Niño to intensify as anomalously intense cyclones (associated instantaneously with the influence of the developing El Niño) act to generate or strengthen equatorial surface westerlies, which in turn favor further warming of the equatorial SST near and east of the date line. We suggest that a small part of the structure of these lag-correlation curves may be determined by such dynamics.

More straightforwardly, the high simultaneous correlations during the peak typhoon season show that predictions of Niño indices can be used to generate predictions of ACE in the western North Pacific, as in current operational statistical forecasts (e.g., Chan et al. 2001; TSR 2005).

In Fig. 4 several characteristics of the ACE distribution-mean, median, 75th and 25th percentiles, and individual extreme values above and below those percentiles-are given, for different ENSO states, using the entire data record. Though the sample size is small, significant differences between the distributions are evident. The entire distribution of ACE per year in El Niño (La Niña) years is shifted to larger (smaller) values, and their differences are statistically significant.

The difference in the ACE patterns in El Niño and La Niña years (Fig. 5) shows an increase in ACE values for most of the basin, with a pronounced maximum at $20^{\circ} \mathrm{N}, 140^{\circ} \mathrm{E}$. There is a clear east-west pattern, with more tropical cyclone activity east of the Philippines and the South China Sea. This is related to the known shift in the genesis position (Chan 2000; Chia and Ropelewski 2002; Wang and Chan 2002) in the western North Pacific induced by ENSO. 


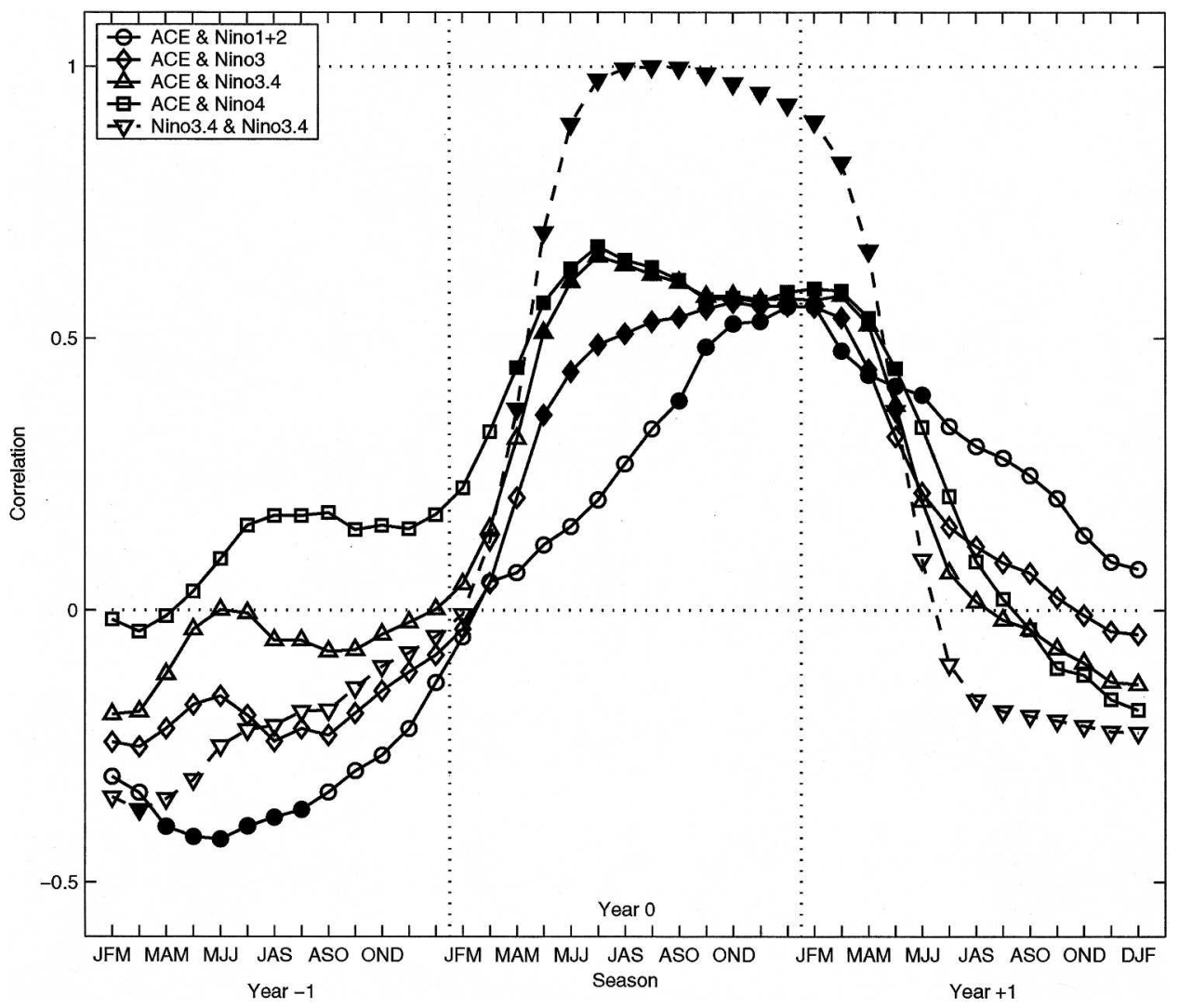

FIG. 3. Lag correlations of ACE (JASO) with Niño indices for different seasons [JFM, FMA, MAM, AMJ, JJA, JAS, JASO, ASO, SON, OND, NDJ, and DJF (months denoted by their first letter)] and lags and autocorrelation of Niño-3.4 JASO for different lags (1970-2002). Significant correlations are indicated by filled symbols.

\section{ACE and tropical cyclone properties}

In this section we explore the relationship of ENSO to other tropical cyclone indices, in particular, the number of tropical cyclones, number of tropical cyclone days, and storm lifetime. The aim is to try to understand how each of these factors relatse to ACE and influences its relation to ENSO.

\section{a. Number of tropical cyclones}

We first examine the relation of the number of tropical cyclones (NTC) per year (tropical depressions not included) with Niño-3.4 (Table 2). The total number of tropical cyclones is not significantly correlated with ENSO, although for strong ENSO events a relationship can be identified (e.g., Chan 1985). By grouping the tropical cyclones by intensity category, following the Saffir-Simpson scale [Saffir 1977; Simpson and Riehl 1981; tropical storms (TS), typhoons (TY, categories 1-2), and intense typhoons (ITY, categories 3-5)], significant correlations of some of the ENSO indices (Table 2) with number of TS (NTS) and number of ITY (NITY) are obtained.
Let us examine the characteristics of the distributions (Fig. 6) of NTC, NTS, number of TY (NTY), and NITY for all years and different ENSO states. There is a tendency toward fewer named tropical cyclones in La Niña years. The distribution in La Niña years is significantly different from that in both El Niño years and neutral years. In contrast, the distribution of NTC is very similar in neutral and El Niño years. A slightly smaller number of tropical storms usually occurs in El Niño years, compared to neutral years (significant result according to the bootstrap calculation), consistent with the significant negative correlation of the number of tropical storms with Niño-3.4 (Table 2). A signal that is statistically significant is the tendency toward more (fewer) intense typhoons (ITY) in El Niño (La Niña) years, consistent with significant positive correlations.

\section{b. Lifetime and number of tropical cyclone days}

We now consider whether the number of tropical cyclone days (TCDAYS) is influenced by ENSO and how this index is related to ACE. The TCDAYS in a year (or season) is the number of 6-h periods during 


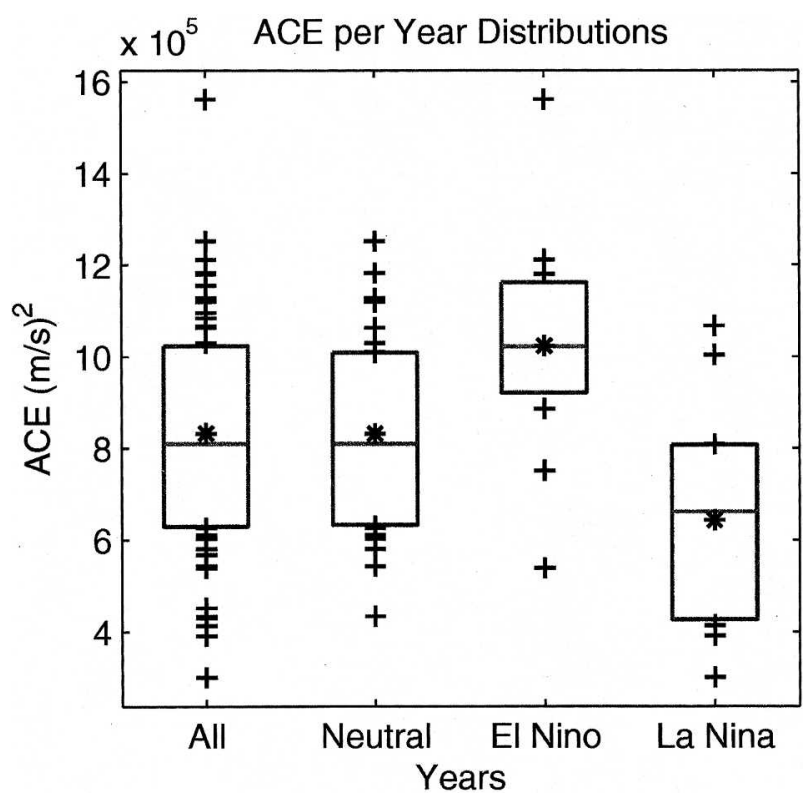

FIG. 4. Distribution of ACE per year in all years, neutral years, El Niño years, and La Niña years. The boxes show the 25th and 75th percentiles, the lines in the boxes mark the median, the asterisks $(*)$ mark the mean, and the crosses mark the values below (above) the 25th (75th) percentiles of the distributions.

which at least one tropical cyclone occurs, divided by 4 and accumulated for the season.

In Fig. 7 the distributions of number of tropical cyclone days for all years and ENSO states are given. There is a very small shift toward more tropical cyclone days in El Niño years (not statistically significant) and a large shift toward fewer tropical cyclone days in La Niña years (statistically significant), contributing to larger (smaller) ACE values in El Niño (La Niña) years.

The correlation of TCDAYS and Niño-3.4 (Table 2) is weaker than that of ACE and ENSO (not shown). The number of tropical cyclone days is apparently one factor contributing to the increase of the tropical cyclone activity, but not the only, or even the dominant, one (as we will see more clearly below). Another interesting point is that the correlation of TCDAYS and Niño-3.4 is higher when averaged over the whole year than when averaged over only the peak season, suggesting that an increase of the number of tropical cyclone days occurs particularly in the early and late seasons in El Niño years.

The shift in the number of tropical cyclone days with ENSO could have two different explanations: either more tropical cyclones occur, or those which do have longer lifetimes. As the NTC and ENSO are not linearly related, we expect the latter explanation to be more correct. To confirm this, we now examine how the typical lifetimes of tropical cyclones are influenced by ENSO.

Figure 8 shows the distribution of tropical cyclone lifetimes in all years and ENSO states. Because the lifetime is discretized to intervals of $6 \mathrm{~h}$, some of the points (outside the 25 th/75th percentiles) represent more than one storm. As expected, there is a shift (statistically significant) toward longer (shorter) lifetimes in El Niño (La Niña) years, as noted by Wang and Chan (2002). The tendency toward longer lifetimes is perhaps to be expected, given the well-documented effect of ENSO on the mean genesis location. In El Niño (La Niña) years, the genesis location shifts southeastward (northwestward), which we expect to result in longer (shorter) periods spent over ocean before making landfall. The average lifetime is significantly correlated with Niño-3.4 indices (Table 2).

\section{c. Intensity}

Next we examine how the distribution of ACE per tropical cyclone-essentially a measure of the product of storm intensity and lifetime for a typical individual storm (i.e., a measure of $\mathrm{ACE}$ that takes out variations in storm number)-differs in different ENSO states (Fig. 9). Similar to the distribution of total ACE per year, the distribution of ACE per tropical cyclone is shifted to larger (smaller) values in El Niño (La Niña) years, with a larger (smaller) standard deviation in El Niño (La Niña) years. The El Niño ACE per tropical cyclone distribution is statistically distinct from both the La Niña and neutral ACE per tropical cyclone distributions. Therefore, the increase (decrease) in ACE per year in El Niño (La Niña) years is mainly due to tropical cyclones with greater ACE per storm, not to a shift in the total number of storms. Still, this result could be due to more intense storms, longer-lived storms, or both, during El Niño years (and the converse in La Niña years).

Our results show then that in El Niño years, there is a large tendency toward more intense typhoons. These intense typhoons dominate ACE and are mainly responsible for the relationship between ACE and ENSO. In La Niña years, there is a slight tendency toward a larger number of tropical cyclones with tropical storm intensity. The distributions of ACE per category (not shown; see Camargo and Sobel (2004)) in the Saffir-Simpson scale (Saffir 1977; Simpson and Riehl 1981) confirm these results.

We now consider whether the number of days with intense tropical cyclones increases in El Niño years. To do that, we count the number of days during which storms of different intensities (tropical storm, typhoon, and intense typhoon) occur. The same calculation is 


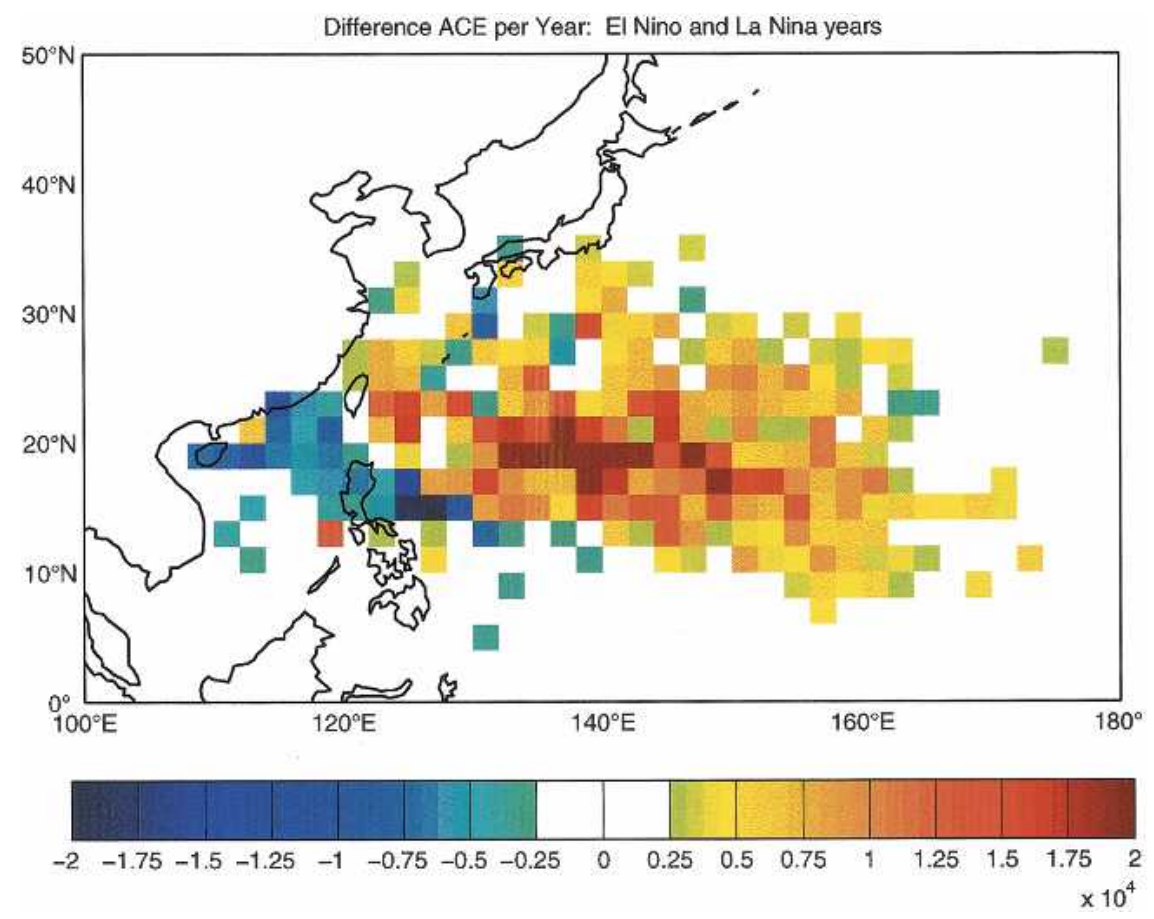

FIG. 5. Difference of ACE per year in El Niño and La Niña years.

also done for all intensities simultaneously. The number of days is weighted by the existing number of cyclones [weighted tropical cyclones days (WTCDAYS)] on that day, so a day with two storms counts as two days, etc.

In El Niño years, there are usually more days with typhoons and intense typhoons than in neutral years, while the distribution in El Niño and neutral years is very similar for the number of tropical storm days (not shown). In contrast, in La Niña years, there is a shift toward a smaller number of weighted tropical cyclone days in all categories (TS, TY, and ITY). The correlations of the number of intense typhoon days are significant and positively correlated with ACE, WTCDAYS, and Niño-3.4 JASO (not shown). The relation between the number of weighted intense typhoon days (WITYDAYS) and Niño-3.4 JASO is shown in Fig. 10. This relationship is particularly strong and consistent over

TABLE 2. Correlations of Niño-3.4 JASO with NTC, NTS, NTY categories 1-2, NITY categories 3-5, TCDAYS, and lifetime in the seasons (year, JJASON, and JASO) in the period 1970-2002. Significant correlations are in boldface.

\begin{tabular}{lccrccc}
\hline \hline Season & NTC & NTS & NTY & NITY & TCDAYS & Lifetime \\
\hline Year & 0.27 & $\mathbf{- 0 . 4 3}$ & 0.07 & $\mathbf{0 . 6 3}$ & $\mathbf{0 . 6 1}$ & $\mathbf{0 . 6 2}$ \\
JJASON & 0.11 & $\mathbf{- 0 . 5 1}$ & 0.01 & $\mathbf{0 . 5 7}$ & $\mathbf{0 . 4 1}$ & $\mathbf{0 . 6 2}$ \\
JASO & 0.03 & $\mathbf{- 0 . 4 6}$ & -0.08 & $\mathbf{0 . 4 6}$ & $\mathbf{0 . 4 6}$ & $\mathbf{0 . 6 0}$ \\
\hline
\end{tabular}

the range of ENSO variability, more so even than the relationship of ENSO and total ACE (cf. Fig. 10 to Fig. 4). Clearly the number and lifetime of intense typhoons is particularly strongly influenced by ENSO.

\section{d. Separate contributions of intensity and lifetime to $A C E$}

We want to quantify the contributions of intensity, lifetime, and number separately to ACE. To do that, we construct three other variables, essentially ACE time series modified so that only either lifetime, intensity, or number, excluding the other two factors, contributes to the variations in the time series. For each individual season, ACE can be written as the sum of the kinetic energies of the individual tropical cyclone: $\mathrm{ACE}=$ $\Sigma_{1}^{N} K_{i}$, where $K_{i}=\Sigma_{t_{0 i}}^{t_{f i}} v(t)^{2}, v(t)$ is the maximum wind speed of the storm at time $t, i$ indices each individual storm, $t_{0 i}$ and $t_{f i}$ are the beginning and end times of the lifetime of storm $i$, and $N$ is the total number of storms in the period under consideration (e.g., JASO of a given year). A measure of the tropical storm intensity is $U_{i}=K_{i} / L_{i}$, where $L_{i}=\Sigma_{t_{0 i}}^{t_{f i}} \Delta t$, with $\Delta t$ as the temporal grid size (here, $6 \mathrm{~h}$ ), is the tropical cyclone lifetime.

The first variable we define is $\mathrm{ACE}_{1}^{*}=\langle L\rangle\langle N\rangle \tilde{U}$, where angle brackets represent an average over all storms and all years in the sample (1970-2002), and the tilde represents an average over the storms in a single season only. Thus $\mathrm{ACE}_{1}^{*}$ has the dimensions and typical 
(a)

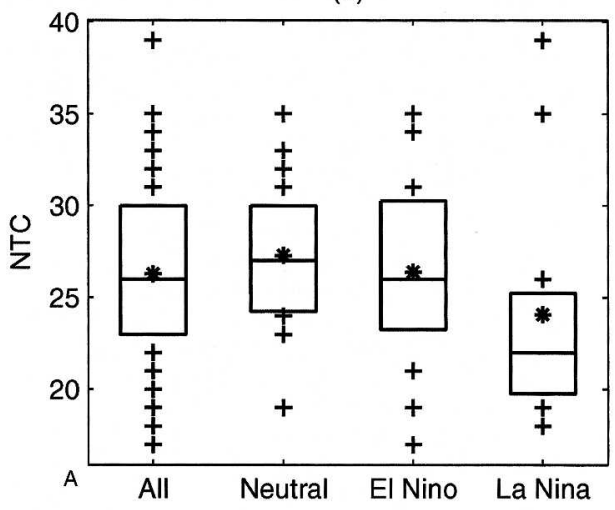

(c)

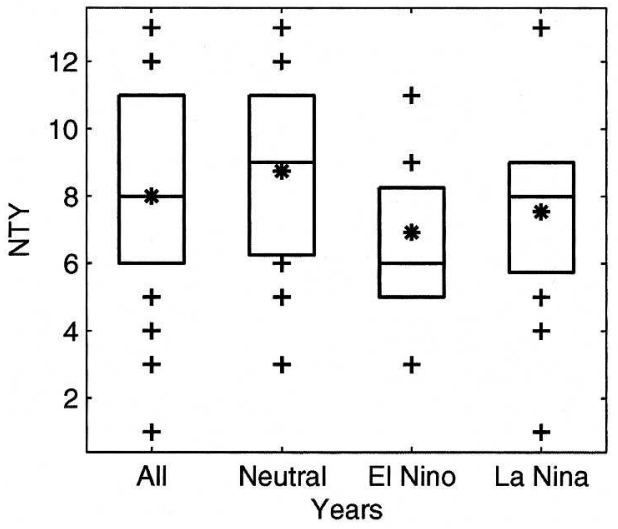

(b)

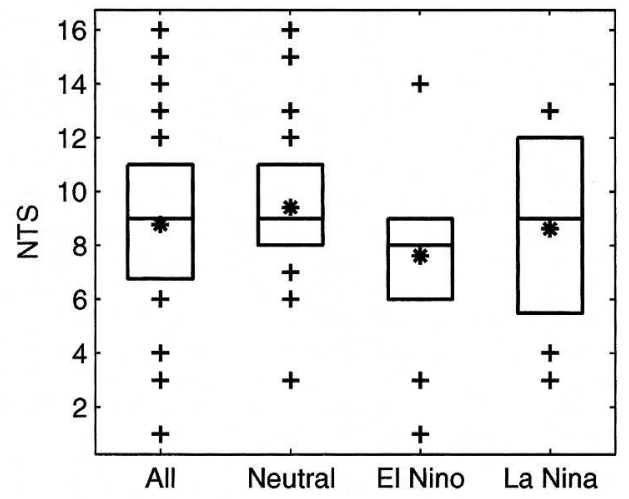

(d)

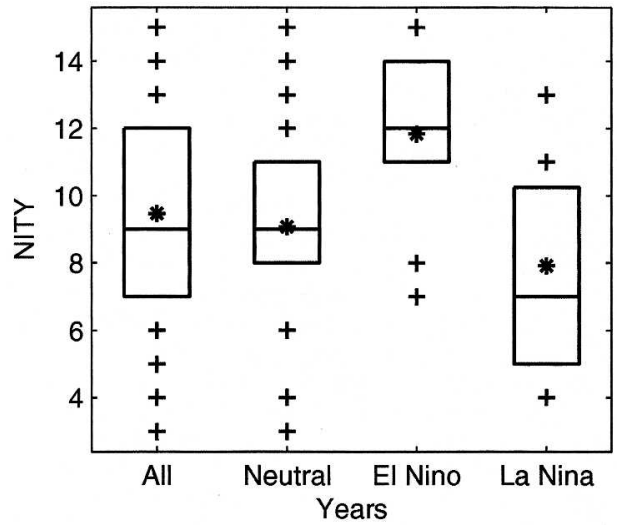

FIG. 6. Distributions of (a) NTC, (b) NTS, (c) NTY categories 1-2, and (d) NITY categories 3-5 in all years, neutral years, El Niño years, and La Niña years. The boxes show the 25th and 75th percentiles, the lines in the boxes mark the median, the asterisks $(*)$ mark the mean, and the crosses mark the values below (above) the 25th (75th) percentiles of the distributions.

magnitude of ACE, but its variations are due only to variations in the mean storm intensity. It represents the ACE that would be obtained if neither the mean lifetime nor the storm number were to vary from one year to the next. The second variable, $\mathrm{ACE}_{2}^{*}=\langle U\rangle\langle N\rangle \tilde{L}$, represents the ACE that would occur if only lifetime were to vary. Finally, we define $\mathrm{ACE}_{3}^{*}=\langle U\rangle\langle L\rangle N$, which represents the ACE that would occur if only the storm number were to vary, with the same mean intensity and lifetime each year.

Table 3 shows the properties of the distributions of $\mathrm{ACE}, \mathrm{ACE}_{1}^{*}, \mathrm{ACE}_{2}^{*}$, and $\mathrm{ACE}_{3}^{*}$ per year, while Table 4 shows their correlations with one another and their correlation with JASO Niño-3.4 for the period 19702002. These tables suggest a complex picture of the relative contributions of lifetime, intensity, and number to the ENSO-related ACE variations. Here, $\mathrm{ACE}_{1}^{*}$, $\mathrm{ACE}_{2}^{*}$ and $\mathrm{ACE}_{3}^{*}$ are all correlated significantly with total ACE. The correlation of total ACE and $\mathrm{ACE}_{3}^{*}$, representing number, is much higher than that of total
ACE and the other two. However, number is not significantly correlated with Niño-3.4 (as we saw before). Somewhat surprisingly, neither is $\mathrm{ACE}_{1}^{*}$, representing intensity, though its correlation with the Niño-3.4 is slightly higher than that of $\mathrm{ACE}_{3}^{*}$ and comes close to the $95 \%$ significance threshold. The variance of $\mathrm{ACE}_{1}^{*}$, on the other hand, is greater by $50 \%$ or more than that of either $\mathrm{ACE}_{1}^{*}$ or $\mathrm{ACE}_{2}^{*}$, suggesting that any intensity variations that are related to ENSO will make relatively large contributions to the total ENSO signal in ACE; $\mathrm{ACE}_{2}^{*}$, representing lifetime, has by far the largest correlation with Niño-3.4 of the three, but the smallest variance (though not much smaller than that of $\mathrm{ACE}_{3}^{*}$, representing number).

The picture we take from all this is that lifetime variations make the largest contribution to the ACE variations associated with ENSO, but intensity and number, in that order, also contribute. To show that intensity and number do contribute despite the insignificant correlation of $\mathrm{ACE}_{1}^{*}$ and $\mathrm{ACE}_{3}^{*}$ with Niño-3.4, 


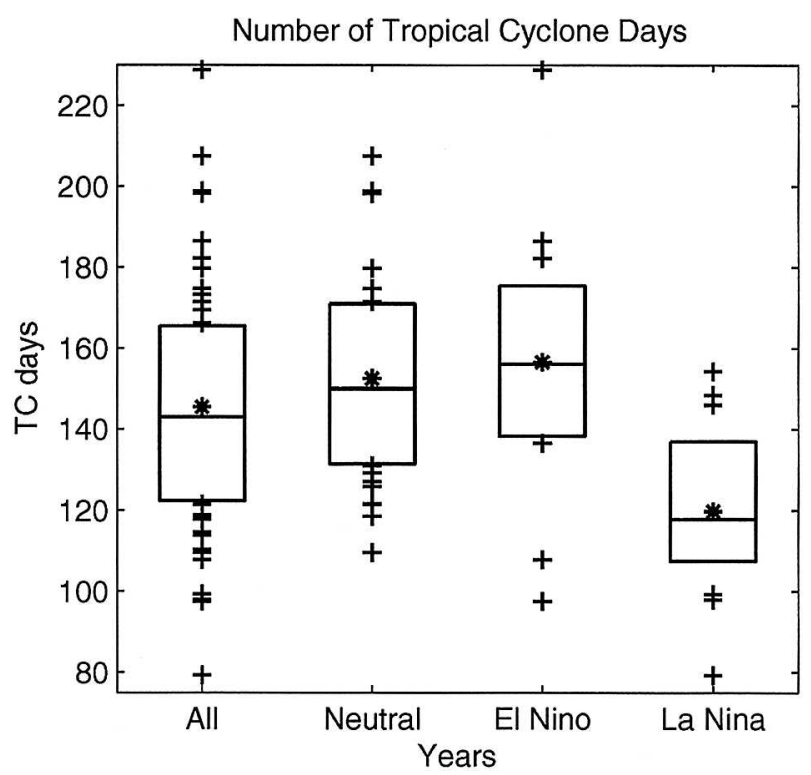

FIG. 7. Same as in Fig. 5, but for distributions of TC days per year in all years and different ENSO states.

we constructed a fourth index, $\mathrm{ACE}_{4}^{*}=\langle L\rangle \Sigma_{1}^{N} U_{i}$. Here $N$ is the interannually varying number and $i$ indices individual storms, so this index includes variations in both intensity and number, but not lifetime. The correlation of $\mathrm{ACE}_{4}^{*}$ and Niño-3.4 is 0.37 , a significant value.

\section{Conclusions}

The influence of ENSO on ACE and related tropical cyclone variables in the western North Pacific has been

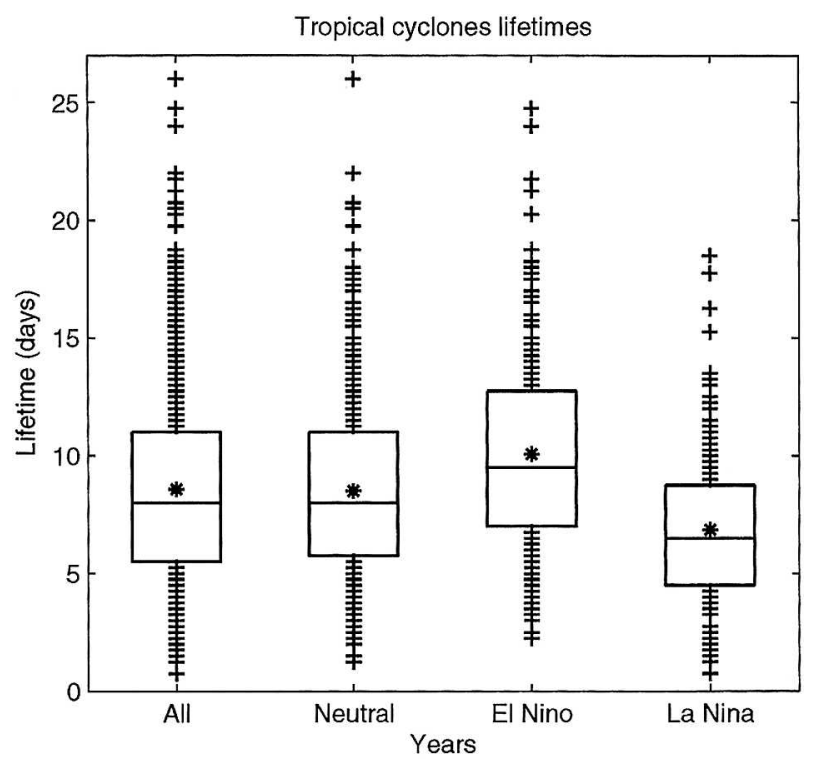

FIG. 8. Same as in Fig. 7, but for TC lifetimes in the period 1970-2002.

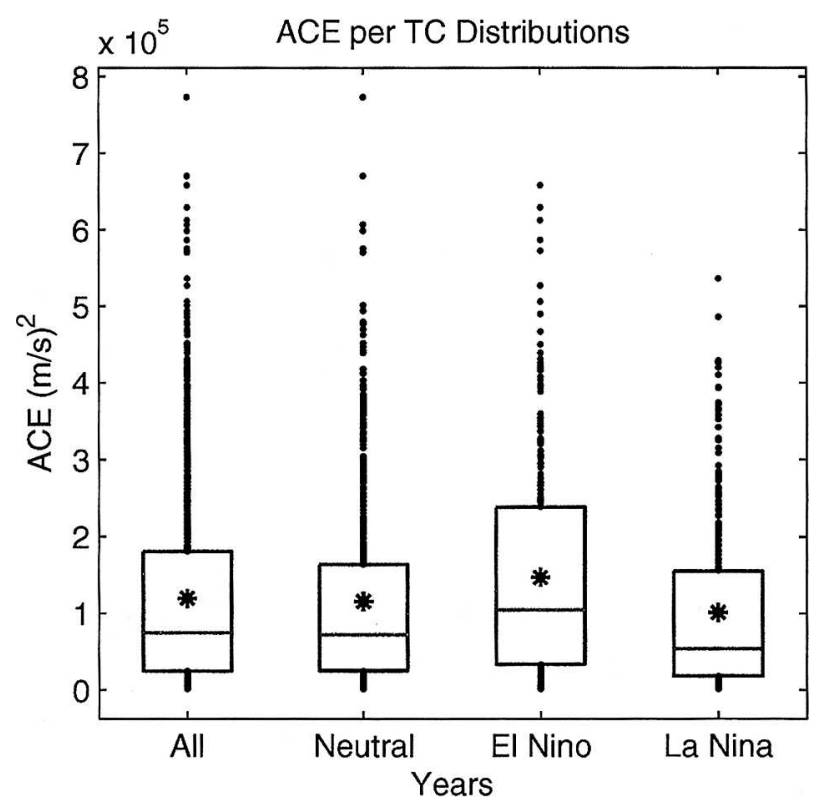

FIG. 9. Same as in Fig. 4, but per TC. There are 1393 TCs in the all-years distribution and 737, 343, and 313 in the neutral years, El Niño years, and La Niña years, respectively.

analyzed in this work. Our main conclusions are that in El Niño years, tropical cyclones have longer lifetimes and, notably, are more intense, with more category-3-5 storms and fewer storms that do not intensify past the tropical storm phase. In La Niña years, there is a tendency toward more short-lived tropical cyclones, many of which do not reach typhoon intensity. Though not shown here, this relationship is consistent over the an-

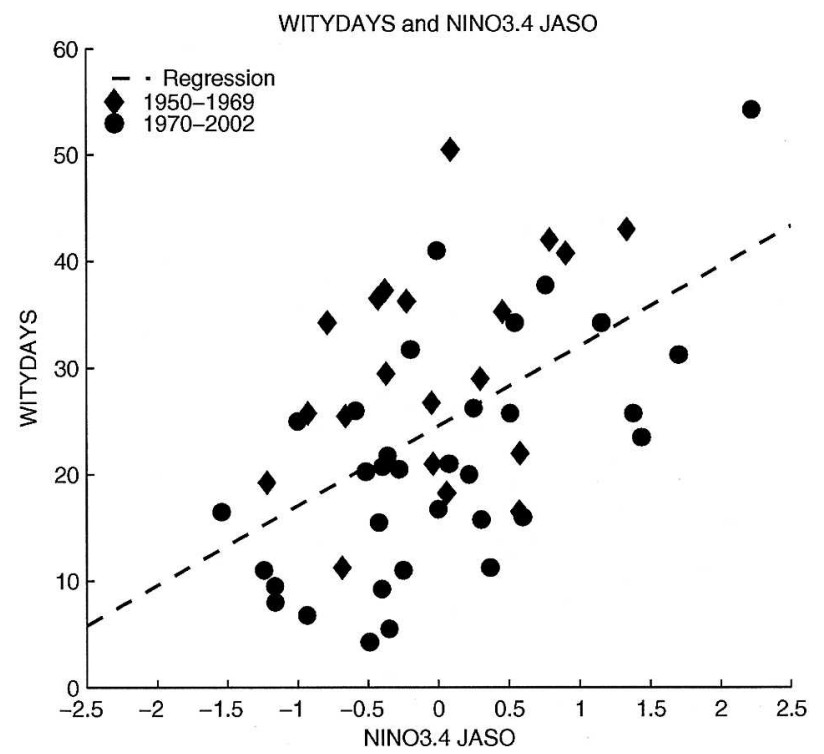

FIG. 10. Same as in Fig. 2, but for weighted number of intense typhoon days per year and Niño-3.4 $\left({ }^{\circ} \mathrm{C}\right)$. 
TABLE 3. Properties of the distributions of ACE, $\mathrm{ACE}_{1}^{*}, \mathrm{ACE}_{2}^{*}$, and $\mathrm{ACE}_{3}^{*}$ per year (in $\mathrm{m} \mathrm{s}^{-2}$ ) in the period 1970-2002.

\begin{tabular}{lrrcr}
\hline \hline \multicolumn{1}{c}{$\times 10^{5}$} & $\mathrm{ACE}$ & $\mathrm{ACE}$ & $\mathrm{ACE}_{2}^{*}$ & $\mathrm{ACE}_{3}^{*}$ \\
\hline Mean & 7.8 & 7.8 & 7.7 & 7.7 \\
Median & 7.4 & 7.8 & 7.6 & 7.5 \\
25th percentile & 6.0 & 7.1 & 7.2 & 6.9 \\
75th percentile & 9.6 & 8.8 & 8.2 & 8.7 \\
Minimum & 3.0 & 4.0 & 5.7 & 5.2 \\
Maximum & 15.6 & 11.8 & 9.9 & 10.1 \\
Std dev & 2.8 & 1.8 & 1.1 & 1.2 \\
\hline
\end{tabular}

nual cycle (Camargo and Sobel 2004) in that ACE for each individual month, at least during the peak season, shows an ENSO signal similar to that obtained by averaging ACE over the peak season or the entire year. The correlation of ACE averaged over JASO and Niño indices in various seasons is nearly as large or larger (depending on which Niño index is examined) when the Niño index lags the ACE by up to six months as when the two are simultaneous. We have argued that while much or even most of this lead of ACE relative to ENSO may be due to the autocorrelation of the Niño indices themselves, not all of it can be explained in this way.

Both the lifetime, intensity, and number effects contribute significantly to the ENSO signal in ACE, though the lifetime effect appears to be the most important of the three. The stronger relationship between TCDAYS and ENSO when the former is averaged over the entire year suggests that the ENSO signals in number, lifetime, or both are particularly manifest in the early and late seasons.

Which measure of storm intensity one wishes to use depends on the scientific question of interest. ACE, being constructed from the squares of the maximum wind speeds of the storms, heavily weights the most intense storms. ACE is related to storm kinetic energy. In the case of the influence on vertical mixing in the ocean, an effect of interest in considering the effect of tropical cyclones on sea surface temperature and their role in global climate (Emanuel 2001), the cube of the

TABLE 4. Correlations of $\mathrm{ACE}, \mathrm{ACE}_{1}^{*}, \mathrm{ACE}_{2}^{*}$, and $\mathrm{ACE}_{3}^{*}$ per year (in $\mathrm{m} \mathrm{s}^{-2}$ ) and their correlations with each other and with Niño-3.4 JASO in the period 1970-2002. Significant correlations are in boldface.

\begin{tabular}{lccc}
\hline & $\mathrm{ACE}_{1}^{*}$ & $\mathrm{ACE}_{2}^{*}$ & $\mathrm{ACE}_{3}^{*}$ \\
\hline $\mathrm{ACE}_{1}^{*}$ & 1 & -0.08 & -0.30 \\
$\mathrm{ACE}_{2}^{*}$ & -0.08 & 1 & 0.04 \\
$\mathrm{ACE}$ & -0.30 & 0.04 & 1 \\
$\mathrm{ACE}$ & $\mathbf{0 . 3 5}$ & $\mathbf{0 . 3 7}$ & $\mathbf{0 . 6 8}$ \\
Niño-3.4 & 0.30 & $\mathbf{0 . 6 2}$ & 0.27 \\
\hline
\end{tabular}

wind speed is the relevant quantity. This will weight the most intense storms even more heavily than ACE does and thus, given the results here, can be expected to have an even stronger ENSO signal.

The physical cause of the intensity signal has not been addressed here. Clearly it is not due to local SST changes, as pointed out by Chan and Liu (2004); the SST warming associated with El Niño events occurs to the east of the region where the storms form. It seems plausible to speculate that the shifts toward both longer lifetimes and greater intensities in El Niño years are due to the eastward shift in genesis location, which we naturally expect to lead to longer tracks over a warm ocean surface. While this seems plausible, particularly in the case of the lifetime effect, it has not been proven. The intensity effect in particular could also be due, to some extent, to other influences of ENSO on the mean regional climate of the western North Pacific.

Acknowledgments. We thank Kerry Emanuel, Michael K. Tippett, Anthony G. Barnston, Chester F. Ropelewski, and Bradfield Lyon for discussions. Suggestions by Johnny C. L. Chan and an anonymous reviewer significantly improved this paper. AHS's participation in this work was supported by a fellowship from the David and Lucile Packard foundation.

\section{REFERENCES}

Atkinson, G., 1977: Proposed system for near real time monitoring of global tropical circulation and weather patterns. Preprints, 11th Technical Conf. on Hurricanes and Tropical Meteorology, Miami Beach, FL, Amer. Meteor. Soc., 645-652.

Barnston, A. G., M. Chelliah, and S. B. Goldenberg, 1997: Documentation of a highly ENSO-related SST region in the equatorial Pacific. Atmos.-Ocean, 35, 367-383.

Bell, G. D., and Coauthors, 2000: Climate assessment for 1999. Bull. Amer. Meteor. Soc., 81, S1-S50.

Camargo, S. J. and A. H. Sobel, 2004: Western North Pacific tropical cyclone intensity and ENSO. IRI Tech. Rep. 04-03, International Research Institute for Climate Prediction, Palisades, NY, 25 pp.

Chan, J. C. L., 1985: Tropical cyclone activity in the northwest Pacific in relation to El Niño/Southern Oscillation phenomenon. Mon. Wea. Rev., 113, 599-606.

_ 1995: Tropical cyclone activity in the western North Pacific in relation to the stratospheric quasi-biennial oscillation. Mon. Wea. Rev., 123, 2567-2571.

— 2000: Tropical cyclone activity over the western North Pacific associated with El Niño and La Niña events. J. Climate, 13, 2960-2972.

— ability in tropical cyclone activity over the western North Pacific. Geophys. Res. Lett., 23, 2765-2767.

— , and K. S. Liu, 2004: Global warming and western North Pacific typhoon activity from an observational perspective. $J$. Climate, 17, 4590-4602.

_ J. E. Shi, and C. M. Lam, 1998: Seasonal forecasting of tropi- 
cal cyclone activity over the western North Pacific and the South China Sea. Wea. Forecasting, 13, 997-1004.

— - - - and K. S. Liu, 2001: Improvements in the seasonal forecasting of tropical cyclone activity over the western North Pacific. Wea. Forecasting, 16, 491-498.

Chen, T. C., S. P. Weng, N. Yamazaki, and S. Kiehne, 1998: Interannual variation in the tropical cyclone activity over the western North Pacific. Mon. Wea. Rev., 126, 1080-1090.

Chia, H. H., and C. F. Ropelewski, 2002: The interannual variability in the genesis location of tropical cyclones in the northwest Pacific. J. Climate, 15, 2934-2944.

Chu, P.-S., and J. Wang, 1997: Tropical cyclone occurrences in the vicinity of Hawaii: Are the differences between El Niño years significant? J. Climate, 10, 2683-2689.

Clark, J. D., and P. Chu, 2002: Interannual variation of tropical cyclone activity over the central North Pacific. J. Meteor. Soc. Japan, 80, 403-418.

CPC, cited 2005: Monthly atmospheric and SST indices. [Available online at http://www.cpc.noaa.gov/data/indices/index. html.]

Dong, K., 1988: El Niño and tropical cyclone frequency in the Australian region and the North-western Pacific. Aust. Meteor. Mag., 36, 219-255.

Elsner, J. B., and K. B. Liu, 2003: Examining the ENSO-typhoon hypothesis. Climate Res., 25, 43-54.

Emanuel, K. A., 2001: The contribution of tropical cyclones to the oceans' meridional heat transport. J. Geophys. Res., 106, $14771-14782$.

Goddard, L., and M. Dilley, 2005: El Niño: Catastrophe or opportunity? J. Climate, 18, 651-665.

JTWC, cited 2005: Joint Typhoon Warning Center best track data site. [Available online at https://metoc.npmoc.navy.mil/jtwc/ best_tracks/.]

Lander, M. A., 1994: An exploratory analysis of the relationship between tropical storm formation in the western North Pacific and ENSO. Mon. Wea. Rev., 122, 636-651.

- and C. P. Guard, 2001: Western North Pacific, North Indian Ocean, and Southern Hemisphere tropical cyclones of 1997. Mon. Wea. Rev., 129, 3015-3036.

Liebmann, B., H. H. Hendon, and J. D. Glick, 1994: The relationship between tropical cyclones of the western Pacific and Indian Oceans and the Madden-Julian Oscillation. J. Meteor. Soc. Japan, 72, 401-411.

Pan, Y. H., 1982: The effect of the thermal state of equatorial eastern Pacific on the frequency of typhoon over the western Pacific (in Chinese with English abstract). Acta Meteor. Sin., 40, 24-34.
Pudov, V. D., and S. A. Petrichenko, 1998: Relationship between the evolution of tropical cyclones in the Northwestern Pacific and El Niño. Oceanology, 38, 447-452.

— genesis in the northwestern Pacific. Izv. Atmos. Oceanic Phys., 37, 576-583.

Ramage, C. S., and A. M. Hori, 1981: Meteorological aspects of El Niño. Mon. Wea. Rev., 109, 1827-1835.

Rodgers, E. B., R. F. Adler, and H. F. Pierce, 2000: Contribution of tropical cyclones to the North Pacific climatological rainfall as observed from satellites. J. Appl. Meteor., 39, 16581678.

Saffir, H. S., 1977: Design and construction requirements for hurricane resistant construction. ASCE Tech. Rep. Preprint 2830, 20 pp. [Available from ASCE Publications, 1801 Alexander Bell Dr., Reston, VA 20191.]

Saunders, M. A., R. E. Chandler, C. J. Merchant, and F. P. Roberts, 2000: Atlantic hurricanes and NW Pacific typhoons: ENSO spatial impacts on occurrence and landfall. Geophys. Res. Lett., 27, 1147-1150.

Sheskin, D. J., 2000: Handbook of Parametric and Nonparametric Statistical Procedures. 2d ed. Chapman \& Hall/CRC, 982 pp.

Simpson, R. H., and H. Riehl, 1981: The Hurricane and Its Impact. Louisiana State University Press, 398 pp.

Sobel, A. H., and E. D. Maloney, 2000: Effect of ENSO and MJO on the western North Pacific tropical cyclones. Geophys. Res. Lett., 27, 1739-1742.

_ , and S. J. Camargo, 2005: Influence of western North Pacific tropical cyclones on their large-scale environment. J. Atmos. Sci., in press.

Trenberth, K. E., 1997: The definition of El Niño. Bull. Amer. Meteor. Soc., 78, 2771-2777.

Troup, A. J., 1965: Southern oscillation. Quart. J. Roy. Meteor. Soc., 91, 490.

TSR, cited 2005: Tropical storm risk. [Available online at http:// tropicalstormrisk.com.]

Wang, B., and J. C. L. Chan, 2002: How strong ENSO events affect tropical storm activity over the western North Pacific. J. Climate, 15, 1643-1658.

Wu, G., and N. C. Lau, 1992: A GCM simulation of the relationship between tropical storm formation and ENSO. Mon. Wea. Rev., 120, 958-977.

Wu, M. C., W. L. Chang, and W. M. Leung, 2004: Impacts of El Niño-Southern Oscillation events on tropical cyclone landfalling activity in the western North Pacific. J. Climate, 17, 1419-1428. 